\title{
Becoming mathematical: Designing a curriculum for a mathematics club
}

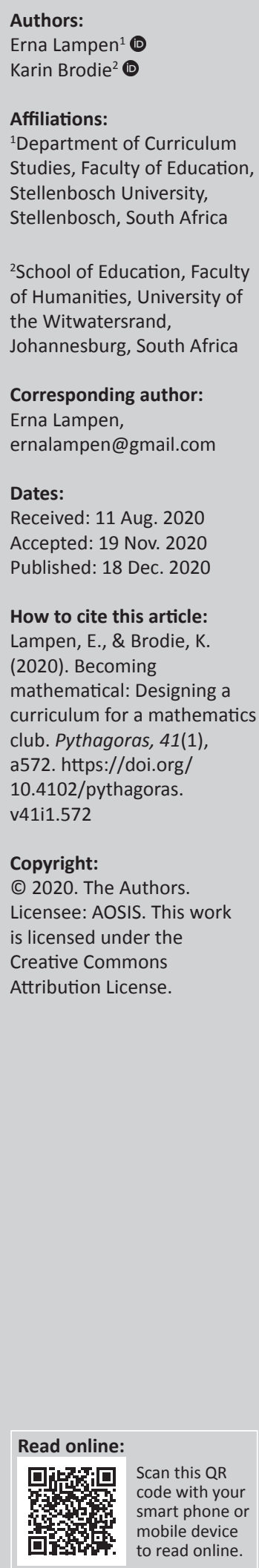

\begin{abstract}
Mathematics clubs are becoming increasingly researched in South Africa, yet what might constitute a curriculum for such clubs has not been discussed. We present and analyse a curriculum design for clubs that we set up and worked with over three years. The goals of the clubs were to foster strong mathematical proficiency, identities and agency among learners through supporting their enjoyment of mathematics as a useful way to make sense of the world. We therefore developed a curriculum where learners could become and be 'mathematical', through drawing on both their everyday reasoning and the mathematics that they learned in school. Our analysis suggests an emergent, responsive curriculum, with tasks that can be categorised as: (1) becoming mathematical with everyday tasks, (2) becoming mathematical about mathematics, (3) being mathematical and making mathematics, and (4) mathematics. We argue that through such a curriculum, we can develop mathematical reasoning on the basis of learners' everyday reasoning in ways that support their mathematical proficiency, identities and agency.
\end{abstract}

Keywords: mathematics clubs; curriculum; becoming mathematical; proficiency; identity; agency.

\section{Introduction}

Mathematics clubs are usually constituted as informal spaces, outside of school, although often based at a school or a university, where learners are encouraged to engage in mathematics as a sense-making activity, to become mathematical problem-solvers, to relate mathematics to real-world situations, and to develop increased enjoyment of mathematics (Prescott \& Pressick-Kilborn, 2015; Schlosser \& Balzano, 2014; Sherman \& Catapano, 2011; Turner, Gutierrez, \& Sutton, 2011). It is also hoped that clubs might improve learners' mathematics achievement (Sherman \& Catapano, 2011) and build on learners' diverse experiences to support them to talk about, interact with and become more confident in mathematics (Amit, Fried, \& Abu-Naja, 2007; Diez-Palomar, Varley, \& Simic, 2006). South African research with clubs, mostly with primary school learners (Stott \& Graven, 2013), works with similar goals. None of the research on clubs discusses a curriculum at the level of decisions about task selection and sequencing.

We developed a number of mathematics clubs in Grades 8-10 that aimed to foster strong mathematical proficiency, identities and agency among learners through supporting their enjoyment of mathematics as a useful way to make sense of the world. In particular, we wanted learners to relate mathematical reasoning in the clubs to both their everyday reasoning and the mathematics that they learn at school. Given that we worked across a number of clubs, we were faced with the challenge of coordinating our activities across the clubs, while remaining responsive to the learners in individual clubs. We therefore found it important to design a club curriculum, with common goals, some common tasks and similar pedagogies across the clubs. The curriculum design principles of mathematics clubs have not been articulated and elaborated in the research, and we have developed some important principles for both task and curriculum design which can contribute to the research literature on mathematics clubs and support mathematics club leaders to reflect on and design their own curricula. The focus of this article is to present and analyse elements of our curriculum and thus to make a contribution to this gap in mathematics club research, in South Africa and internationally.

We write this article in the midst of and as a contribution to debates in South Africa and elsewhere about the extent to which learners' everyday knowledge, or 'life-worlds', should organise and permeate the mathematics curriculum (Hoadley, 2018; Moll, Amanti, Neff, \& Gonzalez, 1992; Young \& Muller, 2013; Zipin, Fataar, \& Brennan, 2015). There is evidence that many teachers who 
try to work with everyday knowledge do not manage to relate it to mathematical knowledge, leaving learners with a denuded sense of mathematics (Hoadley, 2007). At the same time, we know that many learners experience the disciplinary mathematics knowledge of the formal curriculum as alienating and unrelated to their lives and worlds (Brown, Brown, \& Bibby, 2008). Drawing on Young's (Young \& Muller, 2013) notion of powerful knowledge, mathematics is powerful because it provides a gaze on the world different from everyday knowledge, and enables us to enquire into, explain and experience the world in new ways, taking us beyond the present and the particular and enabling us to project possible worlds. It is clear that the current mathematics curriculum in most schools does not achieve such power for most learners. At the same time, drawing on learners' everyday knowledge does not often give access to mathematics as powerful knowledge (Hoadley, 2007). Fataar (2012) argues that pedagogies that support social justice and learner engagement with their schooling require 'intellectually demanding content, on the one hand, and active recognition and working with life world knowledge, on the other' (p. 58). Fataar lays a conceptual basis for such pedagogies but does not show how they might be achieved. Our contribution is to suggest one such pedagogy in mathematics, which links everyday and mathematical reasoning, rather than only content.

Our club curriculum is premised on two assumptions. Firstly, we know that much of mathematics, including current mathematical research, has its seeds in everyday experience and reasoning. Euclidean geometry began with particular, concrete methods of artisans and developed into more general and abstracted work on mathematical objects (Krantz \& Parks, 2014). Research mathematicians often draw inspiration from their everyday experiences and thinking. For example, the well-known Bridges of Königsberg problem originated in everyday experiences and was transformed to mathematics through posing mathematical questions (Gribkovskaia, Halskau, \& Laporte, 2007). Secondly, we know that learners reason powerfully in their everyday lives, particularly learners who live in stressful situations and who regularly solve daily problems of living (e.g. Hemson, 2019). This reasoning must be creative and flexible to support survival, but it is most likely tacit rather than explicit and does not allow for reflection and enquiring beyond the particular. Since learners who are creative outside of school often do not see mathematics as relevant to their lives, we hoped that their everyday reasoning could be utilised and extended to pose mathematical questions. We wanted to both draw on their daily reasoning as a way into mathematics and show them that mathematics can further support how they see and experience the world.

A key element underlying our curriculum is linking everyday reasoning and mathematics, through reasoning in a mathematical way, or as Davis (1996) calls it: the mathematical, which he distinguishes from mathematics. Mathematics is the canon of concepts and activities that have been developed through ages of enquiry. The mathematical 'is that orientation to enquiry which has allowed our mathematics to emerge. It involves noticing of sameness, pattern, and regularity amid one's explorations. It involves comparing, ordering, creating, and naming' (Davis, 1996, pp. 92-93). For our curriculum we formulated three interrelated spaces of action and thinking: the everyday, the mathematical and the mathematics, in order to give access to mathematics as powerful knowledge.

In this article we analyse our club curriculum in order to answer three main research questions:

- Did the curriculum link learners' everyday reasoning to mathematical reasoning, and if so how?

- Did the curriculum support mathematical proficiency, identity and agency? If so, how?

- To what extent was the curriculum responsive? If so, how?

We note that our analysis is of the curriculum only, and not of the ways in which it was taken up by learners. In the next two sections we present our theoretical framing of the curriculum and of our key theoretical constructs: mathematical proficiency, identity and agency.

\section{An emergent, responsive curriculum}

We think about curriculum as a contextualised social process (Cornbleth, 1990), which embodies systemic and sociocultural influences on knowledge, teaching and learning, including ideas about what mathematical knowledge is, how it is created and what values and whose interests are inscribed in and promoted through the curriculum. Our notion of curriculum thus includes and goes beyond particular curriculum content, and even beyond mathematical practices such as generalising, systematising, justifying and communicating mathematics (Ball, 2003). An important premise is that it is not possible to divorce values, particularly epistemological values, from the knowledge that a curriculum seeks to engage learners with. In our case we foreground a mathematical orientation to enquiry as an epistemological value.

Designing a curriculum for a mathematics club may seem contradictory. Mathematics clubs are usually constituted as informal spaces, outside of school, where problem solving and enjoyment are key (Papanastasiou \& Bottiger, 2004; Schlosser \& Balzano, 2014; Sherman \& Catapano, 2011). The idea of a curriculum suggests a formality and prescriptiveness which might hinder these goals and we have not found many articles that carefully describe curriculum decisions taken in clubs. Wallin, Noren and Valero (2019) argue that in Swedish schools, when system-wide, but informal, mathematics clubs became more formalised, with a curriculum and planning guidelines for schools, what they term the 'schoolification' of after-school mathematics clubs, tensions arose for teachers and learners in the clubs as some of the original intentions of engagement and enjoyment were lost. 
We certainly wanted to avoid 'schoolification' in our clubs. However, we wanted to do more than provide a set of challenging and interesting tasks that would support learners to make sense of and enjoy mathematics. We wanted to make careful and thoughtful decisions about the sequence of tasks and about how to develop mathematical identities and agency that support a mathematical orientation to enquiry. We knew that we could not develop a curriculum with linear progression from task to task but expected that sets of tasks taken together, together with a clear set of pedagogical principles, would support our goals. So we did not start with a fully worked out plan, in the usual sense of curriculum. We started with two tasks that embodied some of our overall goals in particular ways, and worked from there, responsively, in relation to learners' engagement with the tasks.

A key element of curriculum as contextualised social process is the extent to which and ways in which the curriculum, with its attendant pedagogy, is responsive to learners (Seah, Andersson, Bishop, \& Clarkson, 2016). While any enacted curriculum is interpreted by teachers and learners (Remillard \& Heck, 2014), who does the interpreting and whose interests are served as the curriculum is enacted are dependent on the responsiveness of the teacher to the learners, and the extent to which the curriculum can shift to take account of learners' ideas. In schools, shifts away from the official curriculum usually occur in the pacing of tasks, and in the addition, deletion or modification of tasks. Bigger shifts might occur when: learners are supported to use and discuss different methods in solving problems, including those not previously seen by the teacher, allowing for learner errors as evidence of the kinds of meanings made by learners and opportunities for new learning, and supporting learners to have conversations that might change the order of the curriculum. These latter curriculum enactments are seen as more responsive to learners' ideas in and about mathematics, and hence position learners as more mathematically agentic, as well as supporting their developing mathematical proficiency and identities.

While an emergent curriculum can be more responsive to learners' engagements, a key concern is how it achieves coherence, which is a key element of powerful knowledge. A standard mathematics curriculum coheres around systematic building of the content, although it is often not experienced as coherent by learners, who see few connections between various topics and little relevance for their own thinking. Noting that the power of powerful knowledge comes from its systematicity (Young \& Muller, 2013), we did not want to jettison the systematic building of a curriculum. However, we saw coherence and systematicity differently, in relation to content and pedagogy.

Our approach to content coherence was to focus on indispensable knowledge from primary school, notably multiplicative relationships between numbers, including fractions, patterned change, including linear change patterns, the properties of operations on numbers, including distribution, associativity and communativity, and spatial properties and relations between points, lines and the figures they form. We wanted to strengthen these content areas for the learners, in ways that are relevant to and supportive of high school content and reasoning, but were very clear that we were not doing additional 'school' teaching in the club, even though we came under intense pressure to do this, from learners, teachers, principals and parents.

We found similar orientations to curriculum in the work of Stott and Graven (2013), based on Valsiner's zone theory. In particular they describe their use of the notion of zones of free movement (ZFM) resulting from the anticipation of learners' 'thinking about the concept being taught, at that moment and in the future ... providing a framework for cognitive activity' (Stott \& Graven, 2013, p. 5). We move away from the zone image with implicit borders in order to signal that everyday life experiences unfold endlessly, and high school learners are already cognitively active in their lives. We found a powerful metaphor in the double helix structure of DNA (Figure 1).

In the metaphor of the DNA helix, we aimed for learners to relate their everyday worlds and mathematics through the common, but developing, ways of reasoning that are relevant in both, and to increasingly twist and condense the spaces between these worlds. The DNA image shows that these worlds can move apart and intersect, all the time being linked. This image captures how we moved systematically between the spaces of everyday reasoning, the mathematical and mathematics, with the aim to shift increasingly over time

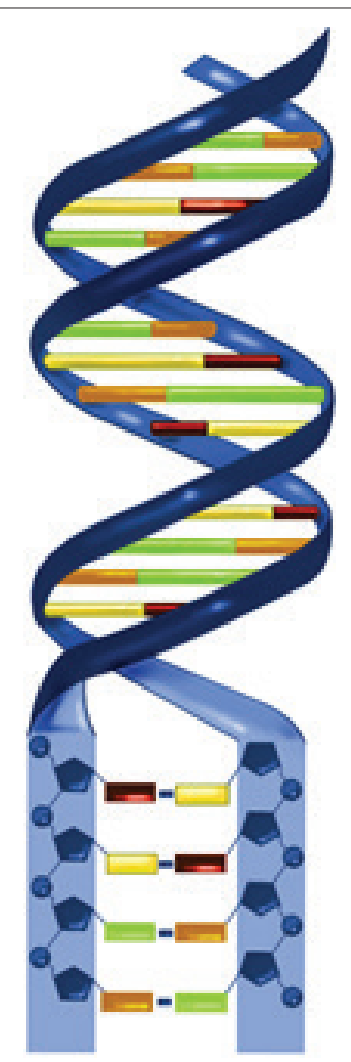

Source: National Institute of General Medical Sciences (n.d., updated 28 Mar 2019). Nucleotides make up DNA. Retrieved from https://images.nigms.nih.gov/Pages/DetailPage. aspx?imagelD2 $=2541$

FIGURE 1: Everyday reasoning, the mathematical and mathematics. 
to becoming mathematical about mathematics.We will use the detailed image of structure at the bottom of the diagram to display our conceptual framework.

We used particular content in the service of developing mathematical orientations to enquiry, in particular to find and use structural properties and relations between numbers, operations and geometric objects, in goal-directed tasks. We moved systematically between the spaces of everyday reasoning, the mathematical and mathematics, with the aim to shift increasingly over time to becoming mathematical about mathematics. So the coherence and systematicity of our curriculum emerged through the relationships between content and pedagogy in relation to the three important spaces for reasoning and action - the everday, the mathematical and mathematics - and through the following elements of our pedagogy:

- All learners can become mathematical enquirers and we have high expectations of all learners and communicate these to them.

- Talk and discussion of ideas are encouraged and learners are shown explicitly how articulating ideas deepens understandings.

- Errors, confusion and asking questions are explicitly supported as normal parts of learning and sense-making in mathematics.

- Mathematical enquiry in both everyday and mathematical contexts is explicitly modelled and valued.

We did not personally design all the tasks that we used in the curriculum. Among the club facilitators we had many years of experience in teaching mathematics and as teacher educators, and we had many tasks that we could use. The design challenge was to select tasks, adapt and modify them to be as responsive as possible to our club learners and our goals, and to work with them in the club so that together they supported the kinds of learning we wanted. We are not claiming that we developed the most appropriate curriculum, or that there might not be other tasks that would also be useful - we certainly expect that there would be. But we do articulate a process that we believe supported a useful club curriculum for our main purposes. We are currently writing up the achievements in the clubs and can show that they did make a difference to learners' achievement, their views of mathematics, their mathematical values and their identities.

\section{Mathematical proficiency, identities and agency}

The conceptual framing for our article comes directly out of the conceptual framing for the design of the clubs and the curriculum. In the clubs we wanted learners to become proficient in mathematics, through building powerful mathematical knowledge and orientations to enquiry, for them to develop mathematical identities as people who choose to use mathematics to make sense of their experiences, and to support learners' mathematical agency, in communicating and making mathematical decisions that make sense to them, and that could be justified in relation to the mathematical and the mathematics. In this article we investigate the extent to which the designed club curriculum might support these three important elements of learning mathematics.

\section{Mathematical proficiency}

Kilpatrick, Swafford and Findell's (eds. 2001) well-known five strands of mathematical proficiency - conceptual understanding, procedural fluency, strategic competence, adaptive reasoning and productive disposition - are expressed as nouns and thus might be thought of as reifications, as competences that learners should display, therefore as part of mathematics. Davis (1996, p. 68) argues: 'the mathematical began to be overshadowed by the mathematics - i.e. the mode of thinking was in some way hidden by the corpus of knowledge that it spawned'. However, the strands of mathematical proficiency can also be thought of as processes and ways of thinking, to reclaim the mathematical as central to mathematics and more closely related to human experience and exploration of the world. From this perspective mathematical proficiency 'emerges from our actions in the world and from our interactions with one another' (Davis, 1996, p. 74). It provides a focus on 'the conversational or dialogical nature of mathematical enquiry that is, the aspect of learning that involves an active and intersubjective questioning of the world', rather than 'a perception of mathematics learning as solitary and monological' (Davis, 1996, p. 94). For example, conceptual understanding is described as knowing 'why a mathematical idea is important and the kinds of contexts in which it is useful' and 'connecting those ideas to what they already know' (eds. Kilpatrick et al., 2001, p. 118), and therefore requires 'comparing, ordering, creating, and naming', key aspects of the mathematical (Davis, 1996, p. 92). Similarly, the other strands, all of which are interrelated, can be seen as reflecting and producing the mathematical, as well as mathematics. More importantly for this article, we were interested in how these strands were seeded in learners' everyday reasoning, and how the five strands of mathematical proficiency could draw on the everyday and build to the mathematical and the mathematics.

Because many of the learners in our clubs had not been previously successful in the predominantly numeric and algorithmic reasoning that school mathematics requires, we wanted them to experience and draw on successes in powerful enquiry in everyday spaces, which we could then relate to mathematics in school. So an important value in our clubs was the similarity between reasoning about mathematics already in the canon and reasoning in extra-mathematical situations. In both our design and our analysis, we looked for possibilities for connections between these, rather than distinctions and dichotomies between mathematical and other forms of reasoning. At the same time, we were aware that many club learners did not like mathematics as they had experienced it in school and our early experiences in the clubs suggested that tasks that looked like school mathematics tended to evoke school-type responses: diminished 
mathematical agency, ignoring their own reasoning, and trying to implement procedures inflexibly. We therefore chose tasks that could set the club apart from school mathematics while trying to build towards understandings of mathematics and becoming mathematical.

\section{Mathematical identities}

Mathematical identity as a research construct can be slippery (Darragh, 2016; Radovic, Black, William, \& Salas, 2018). We define identity as both social and subjective (Radovic et al., 2018) and as an interaction between the social and the personal, where social identity refers to learners' positioning in communities of practice, for example the mathematics class or club, and personal identity refers to learners' personal experiences of mathematics, including their emotions (Gardee \& Brodie, 2019). The five strands of mathematical proficiency working together are all important in supporting learners' personal and social identities, but in particular the strand of productive disposition and how it interacts with the other strands is crucial.

For Kilpatrick et al. (eds. 2001), productive disposition 'refers to the tendency to see sense in mathematics, to perceive it as both useful and worthwhile, to believe that steady effort in learning mathematics pays off, and to see oneself as an effective learner and doer of mathematics' (p. 131). Learners' social identities can be developed as members of a mathematical community of practice oriented towards mathematical enquiry and mathematics, and their personal identities can be developed as effective problem-solvers in and outside of mathematics.

Learners' disabling beliefs about themselves as mathematical thinkers have often been developed through experiences that frame success in mathematics as related to ability rather than to effort and perseverance. We therefore combined our messages of high expectations of all learners with messages about mindset. Dweck (2006) argues that people with fixed mindsets believe that intelligence is fixed, no matter how hard you work, and that success and failure can be attributed to ability rather than effort, while people with growth mindsets believe that intelligence is malleable, grows as you learn and that failure contributes to success and both can be attributed to effort and perseverance. Boaler (2016) develops these notions in relation to mathematics, arguing that successful mathematics learners hold growth beliefs about themselves and about the nature of mathematics and their role in it. They 'search for patterns and relationships and think about connections' and they know that 'math is a subject of growth and their role is to learn and think about new ideas' (2016, p. 34). Research has shown that learners are marginalised when success is attributed to ability, specialness or a 'gift', rather than challenge and perseverence, suggesting that not all learners can be successful in mathematics (eds. Black, Mendick, \& Solomon, 2009; Gardee, 2019).

From a growth mindset perspective, high expectations mean that it is expected that all learners can undertake and persevere with challenging mathematical tasks, with support that continues to challenge them, rather than lowers the task demands (Stein, Grover, \& Henningsen, 1996). Learners' contributions are seen as efforts towards a solution, even (or especially when) there are errors. All learners are supported to persevere to success, where success is defined as finding new directions to think about a task, explaining ideas to others and engaging in mathematical conversations, and making progress in thinking about a task, rather than getting right answers. Our club pedagogy worked to consistently send these messages, both explicitly and implicitly and we have used these concepts to analyse our curriculum.

\section{Mathematical agency}

Agency can be defined in relation to different forms of intentional action or practice or in relation to choosing, consciously or unconsciously, certain actions from a range of other possible actions (Gresalfi, Martin, \& Hand, 2008; Hays, 1994; Noren, 2015). Like identity, agency is not a dispositional attribute of a person, but emerges through social relations between persons and social contexts (Biesta, Priestly, \& Robinson, 2017). People exercise agency by transforming or reproducing their circumstances, influenced by the affordances or constraints made available to them to exercise agency in their situations.

In mathematics education research, agency is sometimes discussed using Andrew Pickering's (1995) distinction between disciplinary and conceptual agency in what he calls the 'dance of agency' (Cobb, Gresalfi, \& Hodge, 2009; Gresalfi \& Cobb, 2006; Sengupta-Irving, 2016). Studying the practices of mathematicians and scientists, Pickering shows how mathematicians utilise disciplinary agency when utilising the current tools and methods of the discipline, and conceptual agency when developing new concepts and methods. All new mathematical ideas are constrained by current disciplinary practices, and require both mathematical autonomy and subjugation to disciplinary norms. Conventional mathematics curricula constrain learners' agency by presenting mathematics content as rules to solve mathematical problems, rendering learners dependent on teachers' approval and validation for their mathematical decisions. So learners are completely subjugated to disciplinary norms without developing mathematical autonomy. This one-sided 'dance' works against mathematical proficiency and the development of robust mathematical identities.

Our definition for mathematical agency is based in strategic competence and adaptive reasoning, the willingness to dance with mathematics by making a plan to solve a problem and to justify the solution through argument and explanation. When confronted with problem tasks, both everyday and mathematical, strategic competence was for us a first agentic response to not knowing. Adaptive reasoning as agency refers to the warrants used in argument or justification: what counts as the warrant in an everyday argument often resides in immediate and local demonstration that is 'true for me' and thus is difficult to argue with. In mathematical reasoning, 


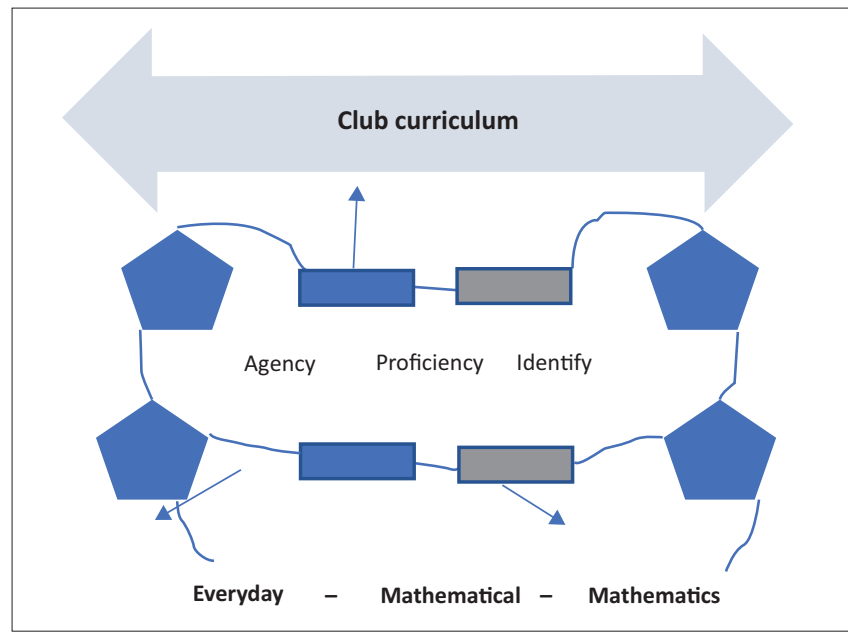

FIGURE 2: Conceptual framework.

supporting arguments go beyond local demonstration and refer to more general conceptual representations and principles, agreed to by the community.

Our conceptual framework is presented diagrammatically in Figure 2. Loosely analogous to the building blocks of the DNA double helix (see the bottom of Figure 1), our curriculum connects the everyday and mathematics spaces, imaged as two strings of pentagons in Figure 2 (analogous to nucleotides). The mathematical space is constituted of mathematical processes, imaged as linking rectangles between the strings and analogous to the hydrogen bonds in DNA that stabilise the two helixes. The role of agency, identity and proficiency is to twist the spaces ever closer around each other, a process called supercoiling in DNA.

\section{The club contexts}

We established a number of mathematics clubs over the three years of the project. In this article we talk about the two clubs that existed for the full time of the project (the actual club time was closer to two and a half years because we did not start at the beginning of the first year). One club was in Johannesburg and one in the Western Cape in two very different schools. The Johannesburg school was a technical high school, located close to the city centre, which selected learners who could attend on the basis of their Grade 8 results and where all learners continued with mathematics until Grade 12 with the intention of moving on to further study in mathematics and science and technical careers. The Western Cape school was located in a township just outside a major town, and was not selective. Most learners in this school, including all of the club learners, took mathematical literacy from Grade 10. Most of the learners in both schools were black ('coloured' in the Western Cape). The medium of instruction in the Johannesburg school was English and in the Western Cape school was Afrikaans. The Western Cape school was located in a violent area, and a number of club sessions could not take place because gang violence had happened recently. School lessons were also sometimes disrupted because of gang activity. All of the learners in the Western Cape school lived near to the school, whereas many
TABLE 1: Club sessions and learners.

\begin{tabular}{lccccc}
\hline Year & Grade & \multicolumn{2}{c}{ Number of sessions } & \multicolumn{2}{c}{ Number of learners } \\
\cline { 3 - 6 } & & Johannesburg & Stellenbosch & Johannesburg & Stellenbosch \\
\hline 2016 & 8 & 9 & 21 & 25 & 35 \\
2017 & 9 & 17 & 20 & 52 & 30 \\
2018 & 10 & 8 & 16 & 27 & 23 \\
\hline
\end{tabular}

of the Johannesburg learners had to travel quite far, often on public transport, sometimes taking more than an hour, which impacted learners' attendance at the club. The mathematics results at both schools were poor, with end of year averages in Grade 10 being $31 \%$ and $28 \%$ at the two schools.

The clubs took place once a week, after school in Johannesburg and on Saturday mornings in the Western Cape, each for about two hours. Table 1 indicates the number of sessions each year in each club and the number of learners signed up for the club. The numbers indicate the maximum number of learners in any session because attendance was voluntary, although we did encourage learners to attend regularly and many did, some for all three years of the project.

Each club was led and managed by each author of this article, one of whom took the lead on developing the curriculum, always in consultation with the other and with other club leaders and facilitators. The Johannesburg club had a second club leader, who took major responsibility in the first year, and each club had about four to six pre-service mathematics teachers and postgraduate students (experienced mathematics teachers), who helped with the club facilitation. The club facilitators were inducted into the club curriculum, including values and pedagogical principles, as outlined above, and met after each club session with the lead facilitators to reflect on and discuss how the curriculum was experienced by the learners, what the challenges were, the extent to which the tasks and pedagogy contributed to the overall curriculum goals and what the next tasks might be. Regular day-long meetings between the leaders of the two clubs - three per year - contributed to the curriculum design process and coherence across the clubs.

While the curricula in the two clubs followed similar design principles and used many of the same tasks, the different contexts sometimes required differences in the curriculum. This was particularly the case in the third year - when the Western Cape learners took mathematical literacy, although we were able to adapt some of the mathematical literacy tasks for the Johannesburg learners. As we present the analysis of the club curriculum, we refer specifically to the Western Cape curriculum, noting that in the Johannesburg club, as well as others, the process and curriculum were similar, with some differences.

\section{Methods of analysis}

Our analysis of the responsiveness of the curriculum comes mostly from planning and reflection field notes. We analysed how often our observations of learner engagement in a club session led to clear decisions to either access a different space 
from the previous task, or to promote specific aspects of identity, agency or proficiency with the subsequent task.

\section{Our analysis consisted of three main steps:}

- We went back to our thinking in designing the curriculum, some of which we had explicitly articulated and written down at the time and some of which was implicit and needed to be articulated and elaborated. We had written notes on each task before taking it to the club, on what mathematics we thought the task would enact, what values it might support, why we chose tasks in different non-mathematical and mathematical contexts, how we thought the learners might approach the tasks, what challenges they might experience and how the club facilitators could deal with the challenges. We also wrote reflections after each club session on how the learners approached the tasks, which parts they enjoyed, what their challenges were and how these were dealt with by the club facilitators. While we cannot make claims about how learners actually engaged without additional evidence, we did find that our reflections influenced the developing curriculum and so we use these for this purpose in the analysis.

- We drew on the above to systematically re-analyse each task in relation to the five strands of mathematical proficiency, and how each task supported movement between the three spaces: everyday, mathematical and mathematics. We wrote up a short memo for each task on why we chose it in relation to previous tasks and how our reflections on the club sessions influenced decisions about subsequent tasks and how we would work with them. At this point in the analysis we thought carefully about how the tasks linked with each other and reflected the goals and values of the curriculum, thus doing a curriculum analysis that went beyond the tasks.

- We analysed each task in relation to the ways that it might support mathematical identities and agency, again writing up memos relating each task to the preceding and subsequent tasks in relation to identity and agency, and used our initial reflections to show how we saw movement across the tasks in these key attributes.

Key elements that link the three spaces with each other are flexibility in using representations and moving between the general and the particular. Everyday reasoning usually embodies local and immediate reasoning, with particular instances and representations. The mathematical usually embodies shared representations and reasoning across instances, while the mathematics involves shared, canonic representation and reasoning flexibly between the particular and the general, with arguments based on defined structure. In relating the mathematical to everyday reasoning, we worked with taking objects and ideas apart and putting them together again, in order to see structure, with part-whole relationships, and with building algorithmic thinking and procedural fluency outside of familiar mathematics content.

In order to analyse for adaptive reasoning, we first identified whether the tasks supported appropriate justification for the learners, and in which spaces the justifications would be placed. For example, in the extra-mathematical tasks, justifications would be constrained to local, immediate reasoning and would fall completely in the everyday space, while mathematics tasks where reasoning is constrained to isolated, rote-learned claims would fall completely in the mathematics space. It became clear from our analysis that we did practically create the third space, the mathematical, by including tasks that allowed basing justifications for everyday reasoning on appropriate mathematical aspects, or basing justifications for mathematical reasoning on appropriate everyday aspects. Secondly, we asked if our pedagogy utilised extra-mathematical tasks to acknowledge immediate and local reasoning supported by demonstration, and then to promote reasoning between learners to move toward the mathematical where reasoning has to take account of multiple instances and consolidate contrasting or contradicting explanations. Similarly we enquired if we utilised mathematics tasks to promote reasoning that accessed the mathematical space, where imagery and analogy supported justification of the mathematics. Thirdly, we reflected on whether tasks and pedagogy were successful in engaging learners in agentic ways - by promoting decision-making, hence becoming strategic in the face of problems, and stimulating sharing and argumentation.

In presenting our findings below, we have included vignettes which make claims about what the learners did in the clubs. We have drawn these from our notes so they are our views of what was happening; we have included them to convey the environments that we experienced in the clubs as we interacted with learners and to 'give life' to our analysis.

\section{Findings: the curriculum analysis}

Our findings show that the tasks can be divided into four distinct groups (a brief description of the tasks is in Appendix 1):

- Becoming mathematical with everyday tasks (tasks 1-5) where we worked mainly between the everyday and the mathematical, except for task 2.

- Becoming mathematical about mathematics (tasks 6-9), where we worked mainly between the mathematics and the mathematical.

- Being mathematical and making mathematics (tasks 10-12) where we worked with all three elements, from everyday to mathematical to mathematics.

- Mathematics (tasks 13-17), where we worked with the mathematical and the mathematics.

At the beginning of the year, we worked more with the relationships between the everyday and the mathematical, in order to draw learners into the club and to make clear the distinctions and relations between club and school mathematics. Towards the end of the year we were working more with the relationships between mathematics and the mathematical. This was because of the learners' development 
of proficiency, identity and agency, as well as their expressed needs to focus more on schoolwork. The analysis suggests that we did develop a progression through the three spaces over time, first linking two of the three spaces (groups 1 and 2), bringing the three together (group 3), and finally working between the two mathematical spaces (group 4).

In each section below we present examples of tasks from each group, with an analysis in terms of the proficiency, identity and agency that the curriculum can support. Each task is presented in the context of the curriculum as a whole, so in analysing the tasks, we also analyse the curriculum.

\section{Becoming mathematical with everyday tasks}

Two tasks in this group ( 1 and 4 ) worked from everyday to mathematical reasoning and two ( 3 and 5) worked from mathematical to everyday reasoning, because we wanted to establish the importance of everyday reasoning from early in the curriculum. Task 1 and Task 2 were the only tasks that we set up before we met the learners in the club and we chose them deliberately as a pair, with the first one intended to make links between the everyday and mathematical and the second between the mathematics and the mathematical.

\section{Task 1}

The task to analyse the structure of a clothes peg in relation to its use was given in the first club session and the learners were unsure of what was expected of them, and obviously did not see this as a mathematics task (Figure 3). However, the discussion yielded what we planned, namely analysis and reflection about the form and function of an everyday object that had resonance with the mathematical.

Agency: The clothes peg task yielded useful information about the learners' agency at the time. From our reflections we saw that showing their knowledge of a clothes peg by drawing was a source of anxiety, probably about being judged. The agency to claim "I don't know!" - as a starting point for learning - seemed not to be an option. Not knowing was a source of shame. Yet the learners engaged in argumentation and they made drawings. We analysed the nature of the responses that we discussed in the post session reflection, and concluded that the learners' arguments about the functions of the various shape features of the pegs had the nature of conjectures that could be supported or refuted. The nature of their arguments was analysed as an aspect of proficiency in everyday reasoning.

To analyse if our pedagogy in the session promoted agency, we had to reflect on whether our engagement with the learners during the session was sensitive and responsive to their emotional experiences in the moment (Frenzel at al., 2019). We knew that the learners were not used to deliberating about everyday objects in the school mathematics classroom. We also knew that if this task alienated them, they may not return to the club. We had to be open to the emotional
The facilitator held up a wooden clothes peg, asking: "Have you used a clothes peg before?" Quiet nodding all round and some sniggering followed. The question was unexpected in a mathematics club. "Please draw a clothes peg, show what you know about clothes pegs". They attempted the drawing, looking furtively at each others' attempts. The drawings varied little, showing mostly the overall shape of a peg:

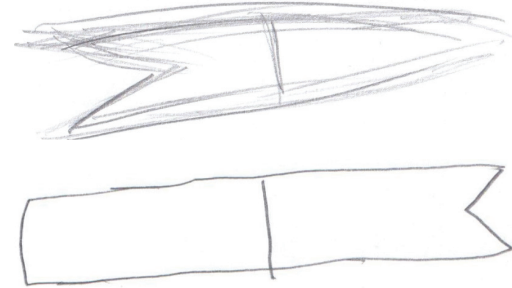

It was clear from their body language that they did not judge their drawings as good representations, and the hushed conversations that accompanied their furtive comparisons confirmed that they realised that they did not know much about the simple object they use often. "How does it look in front?" was answered with gestures of the uses of the front and the back rather than the shape. The drawing on top shows the split back end that is pressed to open the front, while the drawing on the bottom shows the front end split and the back end flat where the fingers press. The line across shows the mechanism for the opening of the peg.

The facilitator then handed out clothes pegs, asking: "How does your drawing compare to the real thing? " The learners opened and closed their pegs, turned them over, viewed them from the side, front and back. In the exploration some pegs came apart and revealed various cutouts. The learners reassembled the parts, noticing how cutouts lined up. "Why do you think a clothes peg is shaped like that?" the facilitator prompted. Soon the discussion became intense.

"I hate the marks it makes on my clothes"

"So, don't push it on so much, just let it touch a little."

"Oh, maybe that is why this part is pointy and not all flat, to only touch the clothes a little."

More playing around, pegging noses and letting the coil spring jump off the parts. There was teasing about the drawings: "This looks like a fish!"

A facilitator asked: "If you showed your drawing to someone in another class, will she recognise it as a clothes peg?"

FIGURE 3: Task 1. Vignette: Clothes peg.

demand on the learners of this engagement with new facilitators and a foreign kind of task. We allowed the learners to support each other emotionally by joking, teasing and playing around with the clothes peg. We acknowledged this as an act of agency rather than disruption, and observed keenly where and when the playful joking opened up opportunities to focus on the functions of the features of the peg, and so sustain enquiry.

Proficiency: Our reflections on the clothes peg task motivated our conception that mathematical proficiency has a mirror construct in everyday spaces. In particular we conceptualised the making and reading of precise and informative diagrams as the counterpart of procedural fluency in working with everyday tasks.

We conjectured on the basis of our post session field notes that the learners' initial proficiency resided in the everyday space, where evidence was provided through demonstration and recollection of experiences. For example, the cylindrical hole through the pins of the peg supposes that washing lines or rods are cylindrical (learners clamped the peg over a pencil 
as evidence) and the v-shaped cut-out at the front ends of the pins have the purpose to minimise the area of the peg that is in contact with the cloth it must secure (they expressed their frustration with peg marks on their own dried clothes). Their diagrams reflected varying proficiency. The learners could acknowledge that the reason for the lack of information and structure in their drawings was not because they could not draw, or that they did not know about clothes pegs, but because they did not 'see' certain information. Playing with the peg with the purpose of enquiry helped them see the peg in a different way. Their later attempts were more proficient in detail and showing structure. The clothes peg became a different object, and the learners had different eyes, at least for the moment. The learners' diagrams of the peg allowed us to talk about an explanatory diagram as used in science and mathematics, as different from a sketch or drawing that one would produce in the arts.

Identity: We viewed the learners' search for function in form in such goal-directed human-made objects as a clothes peg as becoming mathematical. The result of this search could be described as conceptual understanding of the object. Analysing structure and function have underpinned mathematical enquiry through the ages (MacLane, 1986). We saw productive disposition in learners' everyday reasoning about the clothes peg as the expectation of understandable structural relations between forms and their functions, just like productive disposition in mathematics is the expectation that mathematics makes sense and that mathematics problems can be solved (eds. Kilpatrick et al., 2001).

\section{Task 2}

The aim of the second task, Four fours (https://www. youcubed.org/tasks/the-four-4s/), was to bring in mathematics content and show learners how they could reason about mathematics in similar ways as they did with the peg (Figure 4). This task did not achieve our aim of

Before introducing the task, I wrote on the board a few equivalent numerical expressions for 11 , such as $2 \times 3+5 ; 2 \times 5+1 ; 1 \times 11 ; 22 \div 2,3^{2}+2 ; \mathrm{v} 121$. Learners calculated the values easily, in some cases using a calculator. I then asked for different ways to write 12 . Simple alternative expressions were offered, and we had to prompt for expressions with more than one operation. I then stated the problem for the day: Four $4 \mathrm{~s}$ : Write the numbers 1 to 20 using any operations and exactly four $4 \mathrm{~s}$.

The learners stared blankly. They were quiet, no joking. After a while we moved around to observe their productions. Only a few had written anything at all. Most got stuck as they thought they were expected to work systematically from 1 to 20 . We facilitated as best we could: "You don't have to start with one, start anywhere, think what you know about 4 in relation to any other number." "Can you break up the numbers? See how the parts fit together, like you did with the clothes peg?"

After some time we saw $1=4-3 ; 4=4 ; 3=4-1 ; 5=4+1 ; 4 \times 4=16$. Some learners whispered to a neighbour as they compared work, eyes downcast and when they talked to us at all it was hardly audible. Some started jostling and making fun of friends. The atmosphere was very different from the previous week.

We wondered how we could lessen the embarrassment. We worked on, prodding to the point where learners simply did what we suggested. They stayed out long after the tea break was over.

FIGURE 4: Task 2. Vignette: Four fours. promoting the mathematical and foregrounding structure and purpose, and we observed adverse effects on agency, identity and proficiency.

Agency and identity: Our post session notes reveal our deep concern about the effect of this task on learners' well-being. The learners did not experiment with numbers to get a better understanding of the task, and then work systematically and relationally through the numbers, as we had expected them to. We wondered if the constraint was only lack of procedural fluency, but we agreed that their mathematical agency was constrained by the fact that they did not see a purpose for this task. They did not grasp the notion of 'starting with the answer'. Whispered talk was about meaning and purpose, such as what sum must be done, why use only four. Written work showed that they nevertheless tried to make sense as they wrote simple expressions. It became clear to us that learners were not unwilling to engage, but that the problem and its meaning were beyond their comprehension.

Our reflections revealed that we were acutely aware of learners' general embarrasment about their difficulties with the task, as they acted out by making fun of their peers, asked to leave the room, and delayed returning after the break (see also Frenzel et al., 2019). We sensed that these learners, who were currently engaging with algebra in school, expected of themselves to have at least some proficiency with arithmetic, and given that they could not make progress, the activity was not conducive to building positive mathematical identities at this stage. Our reflection on the contrast in learners' engagement with these two tasks supported our conception that willingness to engage in strategic competence is important for agency and willingness to engage in justification can be seen as the seed for identity as a mathematical thinker.

Responsiveness: We understood that we would need to work hard to build their trust through our future engagement with them at the club, without compromising the principles of high expectations and of challenging their thinking. Based on our reflections on how the learners interacted with the first two tasks we decided that we would need to do more work with everyday reasoning and use more tasks that moved between the everyday and the mathematical, before coming back to the mathematics. The learners' specific difficulties with the task to express numbers by using only four $4 \mathrm{~s}$ confirmed the importance of the design principle to focus on discerning structure and purpose. It was evident that the learners did not think about natural numbers as having additive or multiplicative structure, and that operation symbols were merely instructions to act. We spent the time on tasks $3-5$ working with the structure and purpose of everyday thinking in relation to the mathematical.

The facilitators' reflections on the learners' engagement after this group of tasks suggested that they got started on the tasks more readily, they discussed processes and solutions with each other more than they depended on the facilitators, and they were starting to write more readily on their 
scratchpads. After the four successful tasks in this group, we thought that we had initiated a number of important practices in our club: (1) learners showed increased agency as they were reasoning in everyday contexts and beginning to see how some of their reasoning could be seen as mathematical; (2) learners could see that this club was a different enough space from their classrooms that they could begin to take risks; and (3) learners were beginning to trust us and each other to support their thinking, rather than to deny its value. Learners also asked that we help them with their mathematics revision for their mid-year examinations. We therefore imagined, with some trepidation, that we might now be ready to move into school mathematics content more explicitly and to still support what we had begun to build.

\section{Becoming mathematical about mathematics}

In group 2, all four tasks (6-9) went from the mathematics to the mathematical. At this point in the semester, examinations were approaching and the learners asked us to help them with their schoolwork to prepare for the examinations. We responded to their expressed awareness that they did not understand their school mathematics as an indication of developing mathematical identity and agency, because they were asking for more than procedures. In Task 6 and Task 7, we took the opportunity to show the learners that the reasoning mathematically in everyday contexts they had done in the previous taskscan be seen assimilar to reasoning mathematically in classroom mathematics contexts. We drew explicitly on seeds of strategic competence and adaptive reasoning: the fact that learners were willing to start by trying out cases, working systematically and positing reasons for their claims when they worked with the tasks in the first group. They were invited to work in the same way in their school mathematics to guess, test and improve the solutions for linear equations, before 'doing' the algebra that did not yet make sense to them.

\section{Task 6}

This task allowed us to address three fundamental issues. Firstly, the meaning of the scale metaphor, often used in class. Setting up an equation between expressions in mathematics is like balancing a scale in everyday life. Here the objects represent weights, not quantities or physical objects (Figure 5). The question 'How many circles?' is interpreted as 'how many circles will balance the five blocks?', and if not interrogated as algebraic representation, may lead to solutions such as $20 y$. Secondly, we would use the context to emphasise equivalent action on both sides of the scale to maintain the balance, rather than the often-used 'taking numbers over the equal sign' in equations. Thirdly, it is not always the best to start at the top and move linearly. We would emphasise strategic reasoning: start by evaluating the information in relation to the whole.

Identity, agency and proficiency: The learners' evident helplessness when faced with school algebra - the reason for bad marks and anxiety about the approaching examination suggested that we had to do identity work while becoming

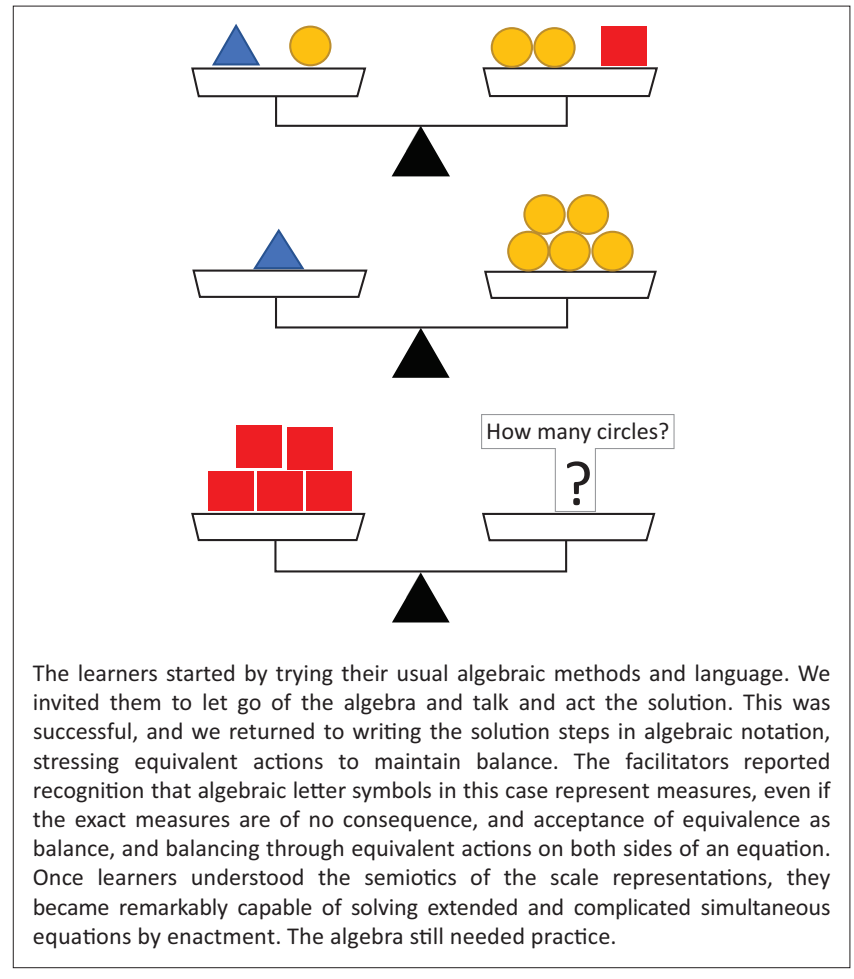

FIGURE 5: Task 6. Vignette: Equations.

mathematical about mathematics. This task's explicit invitation to think in terms of practical balancing actions supported agency. The club was lively with drawing, gesturing and argumentation, promoting learners' identities as capable with the mathematical. We noted that the learners compared strategies with each other and had clear preferences aimed at efficiency. As with the previous extra-mathematical tasks they were not shy or withholding as they tended to be with mathematics content.

The task enabled us to emphasise that algebra can be reasoned and understood and that they are capable to do so. The metaphor created opportunities for us to support becoming mathematical about school mathematics. Although their algebraic proficiency was flawed and rule based, the learners had clearly met the balance metaphor before. We discussed that the objects on the scales, and hence the letter symbols they wrote for them, represent masses, that is, measurements and not physical objects. When they explained algebraic manipulation as 'you have to take over the $y$ and change the sign', we challenged them with the meaning of such action on the scales. Consequently they came to adopt the more mathematical description 'take off a $y$ on both sides', which we supported in algebra talk as well.

Responsiveness: In subsequent work, we responded to their increased willingness to engage in adaptive reasoning through mediation of everyday metaphors, and we continued to relax the usual school mathematics discourse on abstract objects to emphasise processes and invite enactment. With the example 'solve for $x: 2 x+3=12-x$ in their textbooks, we invoked the scale metaphor, for example, with 'what number can you choose to make the left side equal to the right side?' 
We held back on immediate manipulation and encouraged experimentation and guessing and testing. We discussed the structure and relationships between the components of such expressions, for example 'On the left the result gets bigger as you choose bigger numbers for $x$, and on the right it gets smaller. So if one side increases and the other decreases they must be the same somewhere!' Considering how the relationship between two expressions changes as the expressions themselves take different values is at the heart of relational reasoning and allows a kind of estimation in algebra, to support knowing if one is correct. Our post session notes suggest that the learners increasingly experienced that they can talk algebra in meaningful ways, not just voicing symbols, and they gradually supported their manipulation skills by making point checks and reasoning about change and relationships. Before, their only recourse to verification of solutions was to ask a facilitator, or to redo the manipulation steps.

\section{Being mathematical and making mathematics}

The group 3 tasks re-established links between everyday activity from a mathematical perspective and becoming mathematical. In contrast to tasks where the mathematics emerged from the everyday and the mathematical through our questioning and probing, we now planned explicitly to apply mathematics to extra-mathematics tasks. We worked with geometry, responding to the interest and pleasure the learners expressed when they were able to 'make' geometry by considering spatial relations between dots on a page (Task 8).

We analysed whether the tasks allowed us to refer back to aspects of proficiency in previous tasks. In relation to the mathematical, these competences included verifying results by reference to a diagram, and reading a diagram for procedural information. In these tasks we tied in the proficiency developed through tying knots and giving instructions to tie knots in Task 4 and revisited the clothes peg diagram of Task 1 in terms of purpose and structure.

In Task 10 the learners had to fold origami objects based on diagrammatic instructions, and then teach someone else to fold a figure by demonstration and giving instructions. The language of origami, such as hill folds and valley folds, had to be mastered - an aspect of procedural fluency. The activity of folding was followed with relooking at the geometric relationships between fold lines, and the learners had to identify which folds produced parallel or perpendicular lines and which lines produced right angles, specific triangles or specific quadrilaterals. We were therefore able to incorporate many of the ways of working and reasoning we introduced earlier. A new aspect that emerged and needed attention was that the origami task required learners to connect single instructions to a somewhat distant goal, which they struggled with. Origami instructions are essentially algorithms that consist of smaller units. The learners struggled with the algorithmic nature of the origami and would try to get visually similar end products by 'fudging' results. For example, when a fold did not result in equal lengths fitting, they would cut off the excess paper. We related these non-mathematical strategies to similar fudging strategies in their number and algebra work and challenged them to develop precision and accuracy in both cases.

In the planning session we conceptualised unrelated step-following in mathematics as lack of algorithmic thinking. We designed Task 11 to focus on algorithms as step-by-step calculation plans towards a goal, and used an everyday situation (programming a robot to make hot chocolate) to emphasise the need for precise and exact formulation. We reflected on the algorithmic nature of the previous week's origami instructions and followed with a task (Task 12) that required of them to establish a (linear functional) calculation plan for pricing doughnuts, and reflect on their calculation plans for input and output values, and rate of change, as algorithms.

Agency, identity and proficiency: This third group of tasks allowed us opportunities to further discuss with the learners that we make mathematics by the questions we ask in situations. Origami can seem like an art activity, but if we can see geometric shapes and relationships between lines and folds, we can use the knowledge to design new figures. For example, with the inclusion of Task 10 and Task 11 we could challenge them to investigate the fold lines for an origami box and then to fold a new sheet to produce two squares, one with half the area of the other. We revisited the role of writing and making diagrams as means to assist their own thinking, but also to communicate their processes and findings with others. We used action-based discourse (e.g. 'Can you fit two of these squares on the big square?') rather than the more abstract noun-based discourse (e.g. 'What is the area of this one?') as invitation to imagine themselves as agents of making mathematics, rather than simply receiving mathematics instructions to execute. Our reflection notes show that the learners became increasingly engaged in group discussions, and in challenging each other to explain their reasoning along with writing and gesturing. As they showed increased strategic and adaptive reasoning, as well as increased productive disposition in the tasks that related the everyday and mathematical, we wanted to establish these gains also in their engagement with school mathematics.

\section{Mathematics}

In group 4 the tasks responded to the increased pull of school mathematics expressed by the learners. In the school context this time of the year is test time and learners again brought classroom content into the club. Once again algebra was the problem.

In response to the learners' requests for help with the solution of equations, Task 13 required of them to interpret number riddles, such as 'I think of a number; it is a multiple of 7 , the sum of the digits is 8 and the number is smaller than 50'. The riddles incorporated a variety of 
number concepts as well as logic structures such as 'and', 'or', not' and implication. They allowed us to represent the learners' reasoning with mathematics notation, and to establish the relation between operations on numbers, expressions as representations of numbers and equivalent expressions. We asked groups of learners to compose similar riddles for each other, using language that explicitly describes action on numbers and the consequences of such actions. This activity lent itself also to improving mathematics vocabulary, since they revised the meaning of terms like digit, remainder, multiple, twice as many, a third of, etc.

Responsiveness: When we judged that the learners' discourse among themselves was mathematical in the way it described enactment and its consequences for algebraic expressions, we asked them to give such action language expressions for the equations they brought from textbooks. At this stage many learners were able to solve equations of two linear expressions by good inspection strategies, while we supported their algebraic manipulations with reference to the balancing tasks we did earlier. Task 14 continued to build on these ideas in a more formal mathematics context, presenting the learners with a table of expressions, both numerical and algebraic, to be compared and circled if equivalent. Expressions like $12+5=17$ and $2 x+5=17$ had to be related, and $11+6=17$ had to be separated out through arguments about structure. There was no instruction to calculate, simplify or solve, so that the the focus was on the structural composition of the expressions.

Our planning session notes for Task 15 and Task 16 indicate that we wanted to maintain engagement that is mathematical, as we established the spatial-graphical relations between algebraic expressions of different functions (Figure 6). For example, to justify why the graph of $y=2 x$ is steeper than the graph of $y=1 / 2 x$ we expected descriptive talk (e.g. if you

The learners asked for help with their schoolwork. They said that they 'don't understand functions'. In Grade 8, a linear function is defined by the structure of its formula and graphs are plotted point by point. Then the gradient and $y$-intercept are defined and then it is time for 'sums' involving algebraic manipulation. No other functions are introduced and any real-life analogies are addressed only during the end of a learning unit, as applications of functions. We decided to take their request at face value - they wished to understand functions.

We had already dealt with at least one function situation, in the doughnut task. We decided to reuse that task to introduce a function as a relationship between two sets of numbers that change together: the more doughnuts you sell, the more money you make. The function rule is the relationship between the number of doughuts sold and the money collected.

We decided to let them work for a while in small groups to give situations where things increase together, things decrease together, one thing increases and the other decreases. Their examples could be telling about their lives: the longer the light is used, the less electricity is left on the meter; the less it rains the less food there is; the more homework I do, the better I understand. We decided to let them sketch global graphs of the situations and justify their graphs, using their contexts to refer to if the schoolwork is too abstract, and then move back to the school mathematics. Important concepts in both spaces are: dependence of variables, rate of change, input and output values for specific cases.

FIGURE 6: Task 15 and Task 16. Vignette: Planning meeting. multiply a number by 2 the answer is always bigger than if you multiply by half), rather than simply saying two is bigger than half. We further maintained the mathematical by tasks that required the learners to draw global graphs of functions in contexts, and justify their graphs by reasoning about dependence of variables, rate of change and intercepts.

Agency and identity: The learners' requests for specific assistance was a clear act of mathematics agency. We experienced that the learners were aware of the difference between fluency and understanding, and they wanted to understand. Although nearing their examinations, the club learners stayed with the club ethos and did not expect the club to be like school. We cautiously suggest that their identities as being capable of the mathematical were emerging, and that they expected to be able to understand. We resisted schoolification and rather than work with textbook tasks as they are, we designed tasks around the content they brought in, to continue to engage them in being mathematical as we had done previously. We noticed productive disposition when they enthusiastically took up an impromptu non-routine challenge task: write functions to explain how the height above ground level (and then the distance towards the back of the building) changes with the number of steps climbed on the stairwell next to the classroom. They organised themselves in small groups and independently carried out actual measurements. At the end of the session they presented their functions for each others' scrutiny.

\section{Discussion and conclusions}

In working to support access to mathematics for learners who had not experienced success in mathematics previously, we worked to build learners' mathematical proficiency, identities and agency through an emergent and responsive curriculum. Our analysis suggests a number of important principles that we developed through designing our curriculum.

Firstly, we worked out how to build on learners' everyday experiences in ways that go beyond what this usually means. Connecting mathematics to the everyday is often thought of in terms of content and can lead to losing the mathematics in the everyday (Hoadley, 2007, 2018). Our aim with this curriculum was to go beyond the everyday as content and to acknowledge that in people's ways of being in the world, in order to manoeuvre ourselves and make sense of many everyday activities, we order, name phenomena, and notice sameness, pattern and regularity. Such discerments include re-viewing objects in the world in terms of their purpose and structure. This reasoning can serve as a means to develop similar processes in mathematics - the mathematical. The seven tasks in our curriculum that worked with everyday reasoning supported learners to represent their reasoning processes diagrammatically or with physical objects, to question the validity of their own and others' reasoning, and to see and create mathematical order in situations that might not seem mathematical. Building on learners' everyday 
reasoning in these tasks supported their reasoning in the tasks that were entirely in a mathematical context.

Secondly, we found Kilpatrick et al.'s (eds. 2001) five strands of mathematical proficiency useful to conceptualise moving between the mathematical and mathematics, a purpose that they are not usually used for. We asked questions to build learners' strategic competence and adaptive reasoning and supported a less formal and more enactive discourse to answer questions. We aimed to build learners' productive dispositions by giving mindset messages about perseverance, that all people can do mathematics, the importance of errors, and different methods of solving problems, in mathematics and in everyday contexts.

We found two limitations in Kilpatrick et al.'s (eds. 2001) notion of mathematical proficiency: it did not support connections with learners' everyday realities and reasoning and it did not give us a developmental trajectory for building the five strands. We wanted development in relation to linking the everyday with the mathematical and the mathematics. So we articulated how the five strands can be re-interpreted in relation to everyday reasoning, as we have shown in this article. We also found that working within and across the three spaces - everyday, mathematical and mathematics - supported systematic movement through a set of tasks which supported increasing linkages between the three spaces, and development within each one. Given the emergent nature of the curriculum, we did not move linearly from the everyday to the mathematical and the mathematics. We cycled through these in different ways in different tasks, often working with only two, sometimes with all three, in ways that gave the learners experiences of these three spaces, in relationship with each other. The coherence of our curriculum was supported by our overarching goals that we aimed to build in each task, systematically through the three spaces.

Thirdly, we showed how the curriculum path through the three spaces could support the development of mathematical agency and identity. The original tasks and pedagogy showed that learners experienced anxiety and shame at having to admit to not knowing something, and at their weak mathematical skills. As facilitators we were able to see some forms of proficiency in their work, particularly in the everyday space. Being responsive to their strengths and their emotions supported us to develop more tasks and ways of working that did support learners over time to feel more comfortable to try out ideas, ask questions and acknowledge that they wanted to understand and make meaning of the mathematics. So while we cannot point to a direct, linear trajectory, we have suggested that cycling through the spaces might support new forms of agency and identity.

Fourthly, we elaborated our notion of curriculum responsiveness. Had we seen responsiveness as hearing and implementing the learners', teachers' and parents' requests, we would have retaught the school curriculum and not achieved any of our goals of what can be achieved in the distinct space of the mathematics clubs. Rather, we had a set of goals and values that informed our linking of the everyday, the mathematical and mathematics, and we maintained responsiveness to learners in relation to those goals - listening carefully to how they were seeing what we were trying to do. The basis for this work is the assumption that all people have the seeds of mathematical reasoning in their everyday experiences and we could build on these in order to give access to the mathematical and mathematics. But we had to listen sensitively to learners to understand where we had to change direction, and why, in relation to our goals and their experiences of the curriculum.

A final question is the extent to which our curriculum might be useful to others involved in organising mathematics clubs. We have shown that it is possible to design a club curriculum without 'schoolifying', that is, without setting up a formal, predesigned, prescriptive curriculum, which might not be responsive to learners and might move away from the intentions of the club to promote enjoyment and sense-making of mathematics. Importantly, we are not presenting this set of tasks as a design for others to follow. Rather we hope that through the set of principles that we have outlined and our descriptions of how we worked to achieve them, others will find some inspiration and ways of working that will support them in building curricula for their clubs. We continued to use this method of curriculum design in our clubs in the second and third years, and found that our 'system' became even more emergent and responsive, and we were able to engage learners in becoming mathematical.

\section{Acknowledgements Competing interests}

The authors have declared that no competing interests exist.

\section{Authors' contributions}

All authors contributed equally to this work.

\section{Ethical consideration}

Ethical approval to conduct the study was obtained from the University of the Witwatersrand, School of Education Ethics Committee (subcommittee of university committee; Ethical Clearance Number: 2016ECE001S).

\section{Funding information}

Funding was received from National Research Foundation, South Africa (ref no.: CPRR150707123751; grant no.: 99098).

\section{Data availability statement}

Data sharing is not applicable to this article as no new data were created or analysed in this study.

\section{Disclaimer}

The views and opinions expressed in this article are those of the authors and do not necessarily reflect the official policy or position of any affiliated agency of the authors. 


\section{References}

Amit, M., Fried, M. N., \& Abu-Naja, M. (2007). The mathematics club for excellen students as common ground for Bedoiun and other Israeli youth. In B. Sriraman (Ed.), The Montana mathematics enthusiast, 2007 monograph 1: International perspectives on social justice in mathematics education (pp. 75-90). Missoula, MT: Information Age Publishing and the Department of Mathematical SciencesThe University of Montana.

Ball, D. L. (2003). Mathematical proficiency for all students: Towards a strategic research and development program in mathematics education. DRU-2773-OERI. Santa Monica, CA. Retrieved from http://www.rand.org/publications/DRU/ DRU2773.pdf

Biesta, G., Priestly, M., \& Robinson, S. (2017). Talking about education: Exploring the significance of teachers' talk for teacher agency. Journal of Curriculum Studies, 49(1), 38-54. https://doi.org/10.1080/00220272.2016.1205143

Black, L., Mendick, H., \& Solomon, Y. (Eds.). (2009). Mathematical relationships in education: Identities and participation. New York, NY: Routledge.

Boaler, J. (2016). Mathematical Mindsets. San Francisco, CA: Josey-Bass.

Brown, M., Brown, P., \& Bibby, T. (2008). 'I would rather die': Reaons iven by 16-yearolds for not continuing their study of mathematics. Research in Mathematics Education, 10(1), 3-18. https://doi.org/10.1080/14794800801915814

Cobb, P., Gresalfi, M., \& Hodge, L. (2009). An interpretive scheme for analyzing the identities that students develop in mathematics classrooms. Journal for Research in Mathematics Education, 40(1), 40-68.

Cornbleth, C. (1990). Curriculum in context. Basingstoke: Falmer.

Darragh, L. (2016). Identity research in mathematics education. Educational Studies in Mathematics, 93, 19-33. https://doi.org/10.1007/s10649-016-9696-5

Davis, B. (1996). Teaching mathematics: Toward a sound alternative. New York: Garland Publishing Inc.

Diez-Palomar, J., Varley, M., \& Simic, K. (2006). Children and adults talking and doing mathematics: A study of an after school math club. In S. Alatorre, J.L. Cortina, M. Sáiz \& A. Méndez (Eds.), Proceedings of the 28th annual meeting of the North American Chapter of the International Group for the Psychology of Mathematics Education (Vol. 2, pp. 450-456). Mérida: Universidad Pedagógica Nacional..

Dweck, C.S. (2006). Mindset: Changing the way you think to fulfil your potential. London: Robinson

Fataar, A. (2012). Pedagogical justice and student engagement in South African schooling: Working with the cultural capital of disadvantaged students. Perspectives in Education, 30(4), 52-75.

Frenzel, J.M., et al. (2019). Learners' awareness of their emotions and their engagement with mathematics tasks in a mathematics club. Journal of Education 77, 44-59. https://doi.org/10.17159/2520-9868/i77a03

Gardee, A. (2019). Social relationships between teachers and learners, learners' mathematical identities and equity. African Journal of Research in Mathematics,
Science and Technology Education, 23(2), 233-243. https://doi.org/10.1080/1811 Science and Technology
7295.2019.1662641

Gardee, A., \& Brodie, K. (2019). The influence of teachers on learners' mathematical identities. In M. Graven, H. Venkat, A.A. Essien, \& P. Vale (Eds.), Proceedings of the 43rd Conference of the International Group for the Psychology of Mathematics 43rd Conference of the International Group for the
Education (PME), Vol. 2 (pp. 248-255). Pretoria: PME.

Gresalfi, M., \& Cobb, P. (2006). Cultivating students' discipline-specific dispositions as a critical goal for pedagogy and equity. Pedagogies: An International Journal, 1(1), 49-57. https://doi.org/10.1207/s15544818ped0101_8

Gresalfi, M., Martin, T., \& Hand, V. (2008). Constructing competence: An analysis of student participation in the activity system of mathematics classrooms. Educational Studies in Mathematics, 70, 49-70. https://doi.org/10.1007/ s10649-008-9141-5

Gribkovskaia, I., Halskau, Sr. Ø., \& Laporte, G. (2007). The bridges of Königsberg - A historical perspective. Networks, 49(3), 199-203. https://doi.org/10.1002/ net.20159

Hays, S. (1994). Structure and agency and the sticky problem of culture. Sociological Theory, 12(1), 57-72. https://doi.org/10.2307/202035

Hemson, C. (2019). Agency, resilience and innovation in overcoming educational failure. Perspectives in Education, 36(2), 44-60. https://doi.org/10.18820/2519593X/ pie.v36i2.6

Hoadley, U. (2007). The reproduction of social class inequalities through mathematics pedagogies in South African primary schools. Journal of Curriculum Studies, 39(6) 679-706. https://doi.org/10.1080/00220270701261169
Hoadley, U. (2018). Pedagogy in poverty: Lessons from twenty years of curriculum reform in South Africa. London: Routledge. https://doi.org/10.4324/97813 15680927

Kilpatrick, J., Swafford, J., \& Findell, B. (Eds.). (2001). Adding it up: Helping children learn mathematics. Washington, DC: National Academy Press.

Krantz, S.G., \& Parks, H.R. (2014). A mathematical odyssey. Journey from the real to the complex. New York, NY: Springer. https://doi.org/10.1007/978-1-4614-8939-9

MacLane, S. (1986). Mathematics, form and function. New York, NY: Springer-Verlag. https://doi.org/10.1007/978-1-4612-4872-9

Moll, L.C., Amanti, C., Neff, D., \& Gonzalez, N. (1992). Funds of knowledge for teaching: Using a qualitative approach to connect homes and classrooms. Theory into Practice, 31(2), 132-141. https://doi.org/10.1080/00405849209543534

National Institute of General Medical Sciences (n.d., updated 28 Mar 2019). Nucleotides make up DNA. Retrieved from https://images.nigms.nih.gov/Pages/ DetailPage.aspx?imagelD2 $=2541$

Noren, E. (2015). Agency and positioning in a multilingual mathematics classroom. Educational Studies in Mathematics, 89(1), 167-184. https://doi.org/10.1007/ s10649-015-9603-5

Papanastasiou, E.C., \& Bottiger, L. (2004). Maths clubs and their potentials: Making mathematics fun and exciting. A case study of a maths club. International Journal of Mathematics Education in Science and Technology, 35(2), 159-171. https:// doi.org/10.1080/00207390310001638395

Pickering, A. (1995). The mangle of practice: Time, agency and science. Chicago, IL: University of Chicago Press. https://doi.org/10.7208/chicago/9780226668253. 001.0001

Prescott, A., \& Pressick-Kilborn, K. (2015). It's great to be doing maths! Engaging primary students in a lunchtime club. Australian Primary Mathematics classroom, 20(3), 34-39.

Radovic, D., Black, L., William, J., \& Salas, C.E. (2018). Towards conceptual coherence in the research on mathematics learner identity: A systematic review of the literature. Educational Studies in Mathematics, 99, 21-42. https://doi. org/10.1007/s10649-018-9819-2

Remillard, J.T., \& Heck, D.J. (2014). Conceptualizing the curriculum enactment process in mathematics education. ZDM Mathematics Education, 46, 705-718. https:// doi.org/10.1007/s11858-014-0600-4

Schlosser, L.K., \& Balzano, B. (2014). Playing to learn: How after school clubs influence teachers' beliefs about instruction. Sage Open, 4(4), 1-8. https://doi. org/10.1177/2158244014558031

Seah, W.T., Andersson, A., Bishop, A., \& Clarkson, P. (2016). What would the mathematics curriculum look like if values were the focus? For the Learning of Mathematics, 36(1), 14-20.

Sengupta-Irving, T. (2016). Doing things: Organizing for agency in mathematical learning. Journal of Mathematical Behavior, 41, 210-218. https://doi. org/10.1016/j.jmathb.2015.10.001

Sherman, H.J., \& Catapano, S. (2011). After-school elementary school mathematics club: Enhancing achievement and encouraging future teachers. Education Research Quarterly, 35(1), 3-16.

Stein, M.K., Grover, B.W., \& Henningsen, M.A. (1996). Building student capacity for mathematical thinking and reasoning: An analysis of mathematical tasks used in reform classrooms. American Educational Research Journal, 33(2), 455-488. reform classrooms. American Educational Rese
https://doi.org/10.3102/00028312033002455

Stott, D., \& Graven, M. (2013). The dialectical relationship between theory and practice in the design of an after-school mathematics club. Pythagoras, 34(1), Art.\#174, 110 pages. https://doi.org/110.4102/pythagoras.v4134i4101.4174

Turner, E., Gutierrez, R., \& Sutton, T. (2011). Student participation in collective problem solving in an after-school mathematics club: Connections to learning and problem solving in an after-school mathematics club: Connections to learning and 226-246. https://doi.org/10.1080/14926156.2011.595884

Wallin, A., Noren, E., \& Valero, P. (2019). Tensions in the Swedish Fritidshem mathematics curriculum: A policy enactment perspective. Paper presented at the Mathematics Education and Society 10 (MES10), 28 January - 02 February 2019, Hyderabad.

Young, M., \& Muller, J. (2013). On the powers of powerful knowledge. Review of Education, 1(3), 229-250. https://doi.org/10.1002/rev3.3017

Zipin, L., Fataar, A., \& Brennan, M. (2015). Can social realism do social justice? Debating the warrants for curriculum knowledge selection. Education as Change, 19(2), 9-36. https://doi.org/10.1080/16823206.2015.1085610 


\section{Appendix 1}

TABLE 1-A1: Task list and descriptions.

\begin{tabular}{|c|c|c|}
\hline Task no. & Task name & Brief description of task \\
\hline 1 & Clothes peg & $\begin{array}{l}\text { Given a clothes peg, analyse its shape and structure in relation to its function, draw a labelled diagram and } \\
\text { write a description. }\end{array}$ \\
\hline 2 & Four fours & Write the numbers 1 to 20 as expressions with the use of four 4 s exactly. \\
\hline 4 & Tying knots & Interpret diagram instructions to tie basic knots, teach someone else to tie a knot by demonstration. \\
\hline 5 & Pizza & Find the possible combinations of four toppings to make pizzas. \\
\hline 6,7 & School algebra revision & Simplification, factorisation and solving linear equations. \\
\hline 9 & Language of mathematics & Phrases and terms we noticed that learners struggle to understand, including mathematical use of and, or, not. \\
\hline 10 & Origami & Follow diagram instructions and work precisely to fold origami figures. \\
\hline 11 & Algorithms & $\begin{array}{l}\text { Give precise instructions to a robot to make hot chocolate, relate this to origami instructions and algebraic } \\
\text { computation schemes. }\end{array}$ \\
\hline 12 & $\begin{array}{l}\text { - Doughnuts } \\
\text { - Solving linear equations } \\
\text { - Understanding the structure of linear equations }\end{array}$ & $\begin{array}{l}\text { Work from a context to express a sequence of input and output numbers, describe the rate of change, reflect } \\
\text { on role of } m \text { and } c \text { in the formula, reflect on formulae as algorithms. }\end{array}$ \\
\hline 13 & Number sleuths & From word phrases to algebraic expressions. \\
\hline 15,16 & Functions and graphs & Functions and algebraic equations of graphs; relationships between graphs and algebra. \\
\hline 17 & Tesselations with triangles & $\begin{array}{l}\text { Tesselation patterns including parallel lines and similarity groupings. Similarity of triangles; structure, what } \\
\text { makes them similar. }\end{array}$ \\
\hline
\end{tabular}

